\title{
Normospermik bireylerde semen parametreleri ile nötrofil-lenfosit oranı (NLR) ve trombosit-lenfosit oranı (PLR) arasındaki ilișki
}

\author{
The relationship between semen parameters vs. neutrophil-lymphocyte \\ ratio and platelet-lymphocyte ratio in normospermic individuals
}

\author{
Ahmet Gökçe®, Deniz Gülఠ
}

\section{öz}

AMAÇ: Çeşitli hematolojik parametrelerin inflamatuar süreçlerde rol aldığı bilinmektedir. Son zamanlarda bu konuda en çok araştırılan parametrelerden olan nötrofil-lenfosit oranı (NLR) ve trombosit-lenfosit oranının (PLR) semen parametreleri ile ilişkisi hakkındaki bilgiler sınırlıdır. Biz bu çalışmamızda, normospermik bireylerde semen parametreleri ile NLR ve PLR arasındaki ilişkiyi araştırmayı amaçladık.

GEREC ve YÖNTEM: Hastanemiz androloji laboratuarında Ocak 2017 - Aralık 2017 tarihleri arasında yapılmış semen analizleri retrospektif olarak tarandı. Kayıtlarda hemogram sonucu mevcut olan normospermik bireyler çalışmaya dahil edildi. Hemogram sonucu ile semen analizi arasında 6 aydan fazla süre olan olgular çalışma dıșında bırakıldı. Hastaların trombosit sayısı, ortalama trombosit hacmi (MPV), nötrofil sayısı, lenfosit sayısı kayıt edildi ve NLR, PLR hesaplandi. Veriler semen parametreleri ile karşılaştırıldı.

BULGULAR: Çalışmaya dahil edilen 90 hastanın yaş ortalaması $31,50 \pm 7,04$ yil idi. Hastaların hemogram parametrelerinde ortalama trombosit sayıs $237,89 \pm 59,58$, MPV 7,53 $\pm 0,91$, nötrofil sayıs $4046 \pm 1277$, lenfosit sayıs $2277 \pm 692$; semen parametrelerinde semen hacmi $2,80 \pm 0,96 \mathrm{~mL}$, konsantrasyon $69,08 \pm 31,87$, toplam motil sperm sayıs $41,07 \pm 21,36$, idi. Hemogram parametreleri, semen parametreleri ile karşılaştıııldığında aralarında istatistiksel olarak anlamlı korelasyon saptanmadı (Tablo 1).

SONUÇ: Bu çalışmanın sonuçları, sağlıklı normospermik bireylerde semen parametreleri ile NLR ve PLR arasında ilişki olmadığını ve öngördürücü bir belirteç olarak kullanılamayacağını göstermektedir.

Anahtar Kelimeler: Lenfosit, nötrofil, semen parametreleri, trombosit

\section{Gíniș}

İnfertilite, üreme çağındaki çiftlerin yaklaşık \%15'ini etkileyen yaygın bir klinik problemdir ve erkeklerdeki üreme anomalileri veya bozukluklarının infertilitenin yaklaşık

Sakarya Üniversitesi Tıp Fakültesi, Üroloji Anabilim Dalı, Sakarya, Türkiye

Yazışma Adresi/ Correspondence:

Prof. Dr. Ahmet Gökçe

Adnan Menderes Cad. Sağlık Sok No: 195, 54100 Adapazarı/Sakarya, Türkiye

Tel. $\quad+905059378050$

E-mail: aagokce@yahoo.com

Geliş/ Received: $\quad$ 25.07.2019

Kabul/ Accepted: $\quad 29.08 .2019$

\section{ABSTRACT}

OBJECTIVE: It is known that various hematological parameters are involved in inflammatory processes. The data about relationship between semen parameters and neutrophil-lymphocyte ratio (NLR) or platelet-lymphocyte ratio (PLR), which are recently the most researched parameters in this regard, is limited. In this study, we aimed to investigate the relationship between semen parameters and NLR \& PLR in normospermic individuals.

MATRERIAL and METHODS: Semen analysis performed in our hospital andrology laboratory in between January 2017 and December 2017 were retrospectively reviewed. Normospermic individuals who had hemogram test in records, were included in the study. Subjects with a duration of more than 6 months between hemogram results and semen analysis were excluded from the study. Patients' platelet count, mean platelet volume (MPV), neutrophil count, lymphocyte count were recorded and NLR, PLR were calculated. The data were compared with the semen parameters.

RESULTS: Ninety patients included in the study and the mean age was $31.50 \pm 7.04$ years. Mean platelet counts of the patients were $237.89 \pm 59.58$, MPV $7.53 \pm 0.91$, neutrophil count $4046 \pm 1277$, lymphocyte count $2277 \pm 692$; in semen parameters, semen volume $2.80 \pm 0.96 \mathrm{~mL}$, concentration $69.08 \pm 31.87$ and total motile sperm count was $41.07 \pm 21.36$. There was no statistically significant correlation between hemogram parameters and semen parameters (Table 1).

CONCLUSION: The results of this study show that there is no relationship between semen parameters and NLR\&PLR in healthy normospermic individuals and NLR\&PLR can not be used as a predictive marker.

Keywords: Lymphocyte, neutrophil, platelet, semen parameters

\%50’sini oluşturduğu kabul edilir. ${ }^{[1]}$ Erkek infertilitesi, çevresel ve genetik faktörler de dahil olmak üzere çeşitli faktörler ile ilişkilidir. Etiyolojisi ve patofizyolojisinin altında yatan moleküler mekanizmalar hala büyük oranda bilinmese de, üreme sistemi ile bağışıklık sistemi ve inflamatuar patolojiler arasındaki ilişkinin, erkek infertilitesinin patofizyolojisinde önemli bir rol oynadığı bulunmuştur. ${ }^{[2]}$ Erkek genital traktusun içindeki inflamatuar reaksiyonlar, spermatozoa üzerine zararlı etkileri olan oksidatif strese neden olarak sperm DNA'sına zarar verir ve spermatozoada apoptoz görülür. ${ }^{[3]}$

Vücutta sistemik inflamasyonu ölçmek için kullanılan çeşitli biyokimyasal ve hematolojik belirteçler mevcuttur. 
Seminal plazmada, interlökinler (IL), tümör nekrozis faktör-alfa (TNF- $\alpha$ ), interferon gama (IFN- $\gamma$ ), C-reaktif protein (CRP) gibi sitokinler infertiliteye yol açan inflamatuar süreci daha iyi gösterebilir. Ancak, bu inflamatuar belirteçlerin kullanımıyla ilgili teknik zorluklar ve maliyetler, rutin klinik uygulamada kullanımlarını sınılamaktadır. ${ }^{[4]} \mathrm{Bu}$ belirteçlere alternatif olarak, nötrofil-lenfosit oranı (NLR) ve trombosit-lenfosit oranı (PLR), tam kan sayımından hızlı ve ucuz bir şekilde elde edilebilir. Son yıllarda, NLR ve PLR, kanser ve çeşitli sistemik hastalıkların yanı sıra sistemik inflamasyonun bir göstergesi olarak giderek daha fazla kullanılmaktadır. ${ }^{\left[{ }^{[}\right]}$Ancak erkek infertilitesinin göstergesi olan semen parametreleri ile ilişkileri açık değildir.

Biz bu çalışmada normospermik bireylerde semen analizi sonuçları ile NLR ve PLR arasındaki ilişkiyi incelemeyi amaçladık.

\section{GEREÇ VE YÖNTEM}

Hastanemiz androloji laboratuarında Ocak 2017-Aralık 2017 tarihleri arasında yapılmış semen analizleri retrospektif olarak tarandi. Kayitlarda hemogram sonucu mevcut olan normospermik bireyler çalışmaya dahil edildi. Semen analizi için, hastalardan 2-5 günlük cinsel perhiz sonrası kliniğimiz androloji laboratuarında semen numuneleri alındı ve Dünya Sağlık Örgütü (WHO) 2010 sınıflamasına göre değerlendirildi. ${ }^{[6]}$ Hemogram sonucu ile semen analizi arasında 6 aydan fazla süre olan olgular çalışma dışında bırakıldı. Hastaların trombosit sayısı, ortalama trombosit hacmi (MPV), nötrofil sayısı, lenfosit sayısı kayıt edildi. NLR, mutlak nötrofil sayısının lenfosit sayısına bölünmesi ile, PLR ise trombosit sayısının lenfosit sayısına bölünerek ile hesaplandi.

Verilerin analizi için SPSS v.22 paket programı kullanıldı. Tanımlayıcı istatistikler sürekli değişkenler için ortalama \pm standart sapma olarak, kategorik değişkenler ise frekans ve
(\%) şeklinde gösterildi. Değişkenlerin dağılımının normal dağılıma uygun olup olmadığı, Kolmogorov-Smirnov ve Shapiro-Wilk testleriyle değerlendirildi. Korelasyon analizinde normal dağılıma sahip verilerin analizinde Pearson korelasyon testi, normal dağılıma sahip olmayan verilerin analizinde ise Spearman-Rank korelasyon testi kullanıldı. P değeri 0,05'den küçük olan veriler istatistiksel olarak anlamlı kabul edildi.

\section{BULGULAR}

Çalışmaya dahil edilen 90 hastanın yaş ortalaması $31,50 \pm 7,04$ yll idi. Hastaların hemogram parametrelerinde ortalama trombosit sayıs $237,89 \pm 59,58$, MPV 7,53 $\pm 0,91$, nötrofil sayısı $4046 \pm 1277$, lenfosit sayıs $2277 \pm 692$; semen parametrelerinde ortalama cinsel perhiz süresi $3,49 \pm 1,12$ gün, semen hacmi $2,80 \pm 0,96 \mathrm{ml}$, $\mathrm{pH} 7,52 \pm 0,10$, konsantrasyon $69,08 \pm 31,87$, toplam motil sperm oran $\% 58,26 \pm 8,31$, ileri hareketli sperm oranı $\% 49,41 \pm 10,17$, yerinde hareketli sperm oranı $\% 8,85 \pm 4,54$, hareketsiz sperm oranı $\% 41,73 \pm 8,31$, toplam motil sperm sayıs1 $41,07 \pm 21,36$, ileri hareketli sperm sayıs $35,20 \pm 19,27$, yerinde hareketli sperm sayıs $5,87 \pm 4,80$, hareketsiz sperm sayısı 28,02 $\pm 13,09$ idi. Hemogram parametreleri, semen parametreleri ile karşılaştırıldığında aralarında istatistiksel olarak anlamlı korelasyon saptanmadı (Tablo 1).

\section{TARTIȘMA}

Erkek infertilitesinin değerlendirilmesinde en önemli tanı aracı olarak kullanılan semen analizi sonuçlarını etkileyen faktörleri belirlemek, doğru yorum yapabilmek açısından önem arz etmektedir. Ürogenital enfeksiyonlar ve inflamatuar patolojiler erkek infertilitesinin iyi bilinen nedenlerindendir. ${ }^{[7]}$ Erkek infertilitesi vakalarının \%15'inde inflamatuar durumlar rol almaktadır. ${ }^{[8]}$ İdiopatik infertilitesi olan erkeklerin testiküler dokuları incelendiğinde, \%50'sinden

Tablo 1. Semen parametreleri ile hemogram parametrelerinin karşılaştırıldığı korelasyon analizi p değerleri

\begin{tabular}{|c|c|c|c|c|c|c|c|c|c|c|c|}
\hline & Hacim & ph & Konsantrasyon & $\begin{array}{c}\text { Toplam } \\
\text { hareketli } \\
\text { sperm oranı }\end{array}$ & $\begin{array}{c}\text { Ileri } \\
\text { hareketli } \\
\text { sperm } \\
\text { sayısı }\end{array}$ & $\begin{array}{c}\text { Yerinde } \\
\text { hareketli } \\
\text { sperm } \\
\text { sayısı }\end{array}$ & $\begin{array}{c}\text { Hareketsiz } \\
\text { sperm } \\
\text { sayısı }\end{array}$ & $\begin{array}{c}\text { Total } \\
\text { hareketli } \\
\text { sperm } \\
\text { sayısı }\end{array}$ & $\begin{array}{c}\text { Ileri } \\
\text { hareketli } \\
\text { sperm } \\
\text { oranı }\end{array}$ & $\begin{array}{c}\text { Yerinde } \\
\text { hareketli } \\
\text { sperm } \\
\text { oranı }\end{array}$ & $\begin{array}{c}\text { Hareketsiz } \\
\text { sperm } \\
\text { oranı }\end{array}$ \\
\hline Plt & $0.781^{* *}$ & $0.470 * *$ & $0.963 * *$ & $0.814 * *$ & $0.871^{* *}$ & $0.383^{* *}$ & $0.811^{* *}$ & $0.916^{* *}$ & $0.559 * *$ & $0.157^{* *}$ & $0.814^{* *}$ \\
\hline MPV & $0.878 * *$ & $0.936 * *$ & $0.853^{*}$ & $0.511^{*}$ & $0.689 *$ & $0.614^{* *}$ & $0.886 * *$ & $0.950 *$ & $0.130 * *$ & $0.149 *$ & $0.511^{*}$ \\
\hline Nötrofil & $0.752 * *$ & $0.891 * *$ & $0.445^{* *}$ & $0.792 * *$ & $0.511^{* *}$ & $0.950 * *$ & $0.543^{* *}$ & $0.470 * *$ & $0.919 * *$ & $0.716^{* *}$ & $0.792 * *$ \\
\hline Lenfosit & $0.901 * *$ & $0.234 * *$ & $0.981^{*}$ & $0.796 *$ & $0.690^{*}$ & $0.392 * *$ & $0.861 * *$ & $0.885^{*}$ & $0.697 * *$ & $0.135^{*}$ & $0.796^{*}$ \\
\hline NLR & $0.813^{* *}$ & $0.500 * *$ & $0.877^{* *}$ & $0.915^{* *}$ & $0.896 * *$ & $0.564 * *$ & $0.713^{* *}$ & $0.971 * *$ & $0.626 * *$ & $0.353^{* *}$ & $0.915^{* *}$ \\
\hline PLR & $0.583 * *$ & $0.546 * *$ & $0.670 * *$ & $0.564^{* *}$ & $0.606 * *$ & $0.705^{* *}$ & $0.860 * *$ & $0.567^{* *}$ & $0.740 * *$ & $0.506 * *$ & $0.564 * *$ \\
\hline
\end{tabular}


fazlasında lökosit infiltrasyonu saptanmıştır. ${ }^{\left[{ }^{[]}\right.}$Testisleri bağışıklık sisteminin zararlı etkilerinden koruyan, sertoli hücrelerin oluşturduğu kan-testis bariyeridir. İnflamatuar hücreler tarafından üretilen inflamatuar yıkım ürünleri ve serbest oksijen radikalleri (ROS) nedeni ile bu bariyerin hasar görmesi, spermatogenez üzerinde olumsuz etkilere yol açar. Yetersiz antioksidan mekanizmalara sahip hastalarda, ROS sperm membranlarına ve DNA'ya zarar verebilir ve artmış apopitoza neden olabilir. ${ }^{[10]}$

Önceki çalışmalar sistemik inflamatuar süreçlerin semen parametrelerinde anlamlı değişikliklerle ilişkili olduğunu göstermiştir. İnflamatuvar sitokinler olan TNF- $\alpha$ ve IL-6 ile kan-testis bariyerinin bozulmasının, sperm motilitesini anlamlı derecede azalttığ ${ }_{1}$ bulunmuştur. ${ }^{[11,12]}$ Bir başka çalışmada, TNF- $\alpha$ 'nın infertil hastalar arasında azalmış sperm sayıs1, sperm motilitesi ve normal sperm morfolojisi ile anlamlı şekilde ilişkili olduğu gösterilmiştir. ${ }^{[13]}$ Nallella ve ark., varikosel hastalarında IL-6 ve ROS arttığını ve toplam antioksidan kapasitesinin azaldığını; bu nedenle, proinflamatuar bir sitokin olan IL-6 ve oksidatif stresin, bu hastaların infertilite patofizyolojisinde rol oynayabileceğini bulmuşlardır. ${ }^{[14]}$ Ek olarak serum sitokinlerindeki artışın hipotalamik-hipofizer-testis aksı üzerinde zararlı etkileri olabileceği, testis fonksiyonunu ve fertiliteyi olumsuz yönde etkileyebileceği öne sürülmüştür. ${ }^{[15]}$

Sistemik inflamasyonu ölçmek için kullanılan çeşitli biyokimyasal ve hematolojik belirteçler vardır. Bu belirteçlerin birçoğunun sonuç vermesi uzun zaman alır, maliyetlidir ve klinik kullanımı sınırlıdır. NLR son yıllarda sistemik inflamasyonun sık kullanılan bir belirteci olmuştur. ${ }^{[5]}$ Tam kan sayımından elde edilen nötrofil sayısını lenfosit sayısına bölerek kolayca hesaplanabilen ucuz, pratik ve yaygın olarak kullanılan bir belirteçtir. Literatürde çeşitli kanserlerde NLR'nin klinik önemini araştıran çok sayıda yayın bulunmaktadır. ${ }^{[16]}$ Ayrıca NLR'nin hipertansiyon, diyabet, metabolik sendrom, böbrek hastalıkları, inflamatuar hastalıklar ve romatolojik hastalıklarda klinik önemini araştıran birçok çalışma bulunmaktadır. ${ }^{[17]}$ Güneş ve ark. NLR ve buna ek olarak PLR'nin akut inflamatuar bir durum olan testis torsiyonunun tanısındaki prediktif yeteneğini araştırmış ve sadece skrotal duyarlılık ile bu oranlar arasında istatistiksel olarak anlamlı bir ilişki bulmuşlardır. ${ }^{[18]}$

Sistemik enfeksiyon sonrası nötrofili ve lenfositopeni ortaya çıktığı için ${ }^{[19]}$, kronik inflamasyonlu hastalarda NLR ve PLR'deki artış seminal parametreleri de etkileyebilir. Literatürde NLR ve PLR ile yapılmış birçok çalışma olmasına rağmen semen parametreleri ile ilişkisini değerlendiren çalışmalar sınırlıdır. Yücel ve ark.'nın yaptığı çalışmada TESE operasyonu sonrası sperm elde edilen ve edilmeyen gruplar arasında NLR ve PLR oranları karşılaştırılmış ve sperm elde edilmeyen grupta bu değerler anlamlı olarak yüksek saptanmıştır. ${ }^{[20]}$ Ateş ve ark.'nın yaptığı bir çalışma$\mathrm{da}$ ise mikrocerrahi subinguinal varikoselektomi uygulanan hastalarda cerrahinin semen parametreleri üzerindeki başarısını öngörmede NLR bağımsız prediktif faktör olarak saptanmıştır. ${ }^{[21]}$ Normozoospermik grup ile anormal semen analizi grubunun karşılaştırıldı̆̆ı bir başka çalışmada, semen parametrelerinden herhangi biri ile NLR veya PLR arsinda anlamlı bir farklılık bulunmamıştır. Ayrıca nötrofil sayısı veya lenfosit sayısında da gruplar arasında fark saptanmamıştır. ${ }^{[4]}$ Benzer şekilde yakın zamanda yayınlanmış diğer bir çalışmada anormal sperm analizi sonuçları olan hasta grubu ile normozoospermik gruplar arasında nötrofil ve lenfosit sayısı açısından fark bulunmamış ve seminal parametreler ile NLR, PLR arasında da korelasyon saptanmamıştır. ${ }^{[22]}$ Bizim çalışmamızda; literatürdeki çalışmalardan farklı olarak tümü normozoospermik bireyler arasında semen parametreleri ile NLR ve PLR karşılaştırılmış olup anlamlı bir ilişki saptanmamışıı. Ayrıca trombosit sayısı, MPV, nötrofil sayısı ve lenfosit sayısı ile semen parametreleri arasında da korelasyon bulunmamıştır. Çalışmanın retrospektif olması ve hasta sayısının azlığı kısıtlayıcı faktörlerden sayılabilir.

\section{SONUÇ}

Bu çalışmanın sonuçları, sağlıklı normospermik bireylerde semen parametreleri ile NLR ve PLR arasında ilişki olmadığını ve öngördürücü bir belirteç olarak kullanılamayacağını göstermektedir. Konuyla ilgili yapılacak daha büyük serili çalışmalara ihtiyaç vardır.

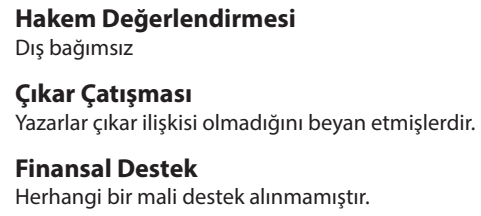

\section{Peer-review}

Externally peer-reviewed.

Conflict of Interest

No conflict of interest was declared by the authors.

Financial Disclosure

No financial disclosure was received.

\section{KAYNAKLAR}

1. World Health Organization (WHO). WHO Manual for the Standardised Investigation and Diagnosis of the Infertile Couple, Cambridge: Cambridge University Press; 2000.

2. Fraczek M, Kurpisz M. Cytokines in the male reproductive tract and their role in infertility disorders. J Reprod Immunol 2015;108:98-104. [CrossRef]

3. Azenabor A, Ekun AO, Akinloye O. Impact of inflammation on male reproductive tract. J Reprod Infertil 2015;16:123-9. https://www.ncbi. nlm.nih.gov/pmc/articles/PMC4508350/ 
4. Aykan S, Canat L, Gönültaş S, Atalay HA, Altunrende F. Are There Relationships between Seminal Parameters and the Neutrophil-toLymphocyte Ratio or the Platelet-to-Lymphocyte Ratio? World J Mens Health 2017;35:51-6. [CrossRef]

5. Imtiaz F, Shafique K, Mirza SS, Ayoob Z, Vart P, Rao S. Neutrophil lymphocyte ratio as a measure of systemic inflammation in prevalent chronic diseases in Asian population. Int Arch Med 2012;5:2. [CrossRef]

6. World Health Organization (WHO). WHO Laboratory manual for the examination and processing of human semen, 5th ed. Geneva: WHO Department of Reproductive Health and Research; 2010.

7. Weidner W, Pilatz A, Diemer T, Schuppe HC, Rusz A, Wagenlehner F. Male urogenital infections: Impact of infection and inflammation on ejaculate parameters. World J Urol 2013;31:717-23. [CrossRef]

8. Haidl G, Allam JP, Schuppe HC. Chronic epididymitis: impact on semen parameters and therapeutic options. Andrologia 2008;40:92-6. [CrossRef]

9. Bachir BG, Jarvi K. Infectious, inflammatory, and immunologic conditions resulting in male infertility. Urol Clin North Am 2014;41:6781. [CrossRef]

10. Hedger MP. Testicular leukocytes: what are they doing? Rev Reprod 1997;2:38-47. [CrossRef]

11. Lampiao F, du Plessis SS. TNF-alpha and IL-6 affect human sperm function by elevating nitric oxide production. Reprod Biomed Online 2008;17:628-31. [CrossRef]

12. Zhang H, Yin Y, Wang G, Liu Z, Liu L, Sun F. Interleukin-6 disrupts bloodtestis barrier through inhibiting protein degradation or activating phosphorylated ERK in Sertoli cells. Sci Rep 2014;4:4260. [CrossRef]

13. Zalata A, Atwa A, El-Naser Badawy A, Aziz A, El-Baz R, Elhanbly S, Mostafa T. Tumor necrosis factor-a gene polymorphism relationship to seminal variables in infertile men. Urology 2013;81:962-6. [CrossRef]
14. Nallella KP, Allamaneni SS, Pasqualotto FF, Sharma RK, Thomas AJ, Agarwal A. Relationship of interleukin- 6 with semen characteristics and oxidative stress in patients with varicocele. Urology 2004;64:10103. [CrossRef]

15. Hales DB. Testicular macrophage modulation of Leydig cell steroidogenesis. J Reprod Immunol 2002;57:3-18. [CrossRef]

16. Guthrie GJ, Charles KA, Roxburgh CS, Horgan PG, McMillan DC, Clarke SJ. The systemic inflammation-based neutrophil-lymphocyte ratio: experience in patients with cancer. Crit Rev Oncol Hematol 2013;88:218-30. [CrossRef]

17. Gürağaç $A$, Demirer Z. The neutrophil-to-lymphocyte ratio in clinical practice. Can Urol Assoc J 2016;10:141. [CrossRef]

18. Güneş $M$, Umul M, Altok M, Akyuz M, İşoğlu CS, Uruc F, et al. Predictive role of hematologic parameters in testicular torsion. Korean $\mathrm{J}$ Urol 2015;56:324-9. [CrossRef]

19. Zahorec R. Ratio of neutrophil to lymphocyte counts: rapid and simple parameter of systemic inflammation and stress in critically ill. Bratisl Lek Listy 2001;102:5-14.

20. Yucel C, Keskin MZ, Cakmak O, Ergani B, Kose C, Celik O, et al. Predictive value of pre-operative inflammation-based prognostic scores (neutrophil-to-lymphocyte ratio, platelet-to-lymphocyte ratio, and monocyte-to-eosinophil ratio) in testicular sperm extraction: a pilot study. Andrology 2017;5:1100-4. [CrossRef]

21. Ates E, Ucar M, Keskin MZ, Gokce A. Preoperative neutrophil-tolymphocyte ratio as a new prognostic predictor after microsurgical subinguinal varicocelectomy. Andrologia 2018:e13188. [CrossRef]

22. Kucukdurmaz F, Temiz Dogan N, Olmez C, Demir BT, Bilecan E, Resim S. Seminal parameters are not related to inflammatory markers (Neutrophilto-lymphocyte, platelet-to-lymphocyte and monocyte-toeosinophil ratios) and plasma vitamin $D$ levels in infertile men. Androl Bul 2019;21:1-5. [CrossRef] 